\title{
Analysis of Active Sensor Discrimination Requirements for Various Missile Defense Scenarios Final Report 1999 (99-ERD-080)
}

U.S. Department of Energy

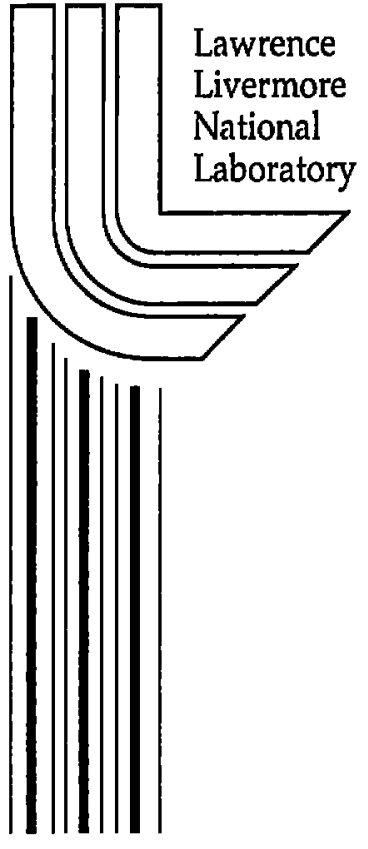

Arno G. Ledebuhr, Lawrence C. Ng, and

Richard J. Gaughan

February 15, 2000 


\section{DISCLAIMER}

This document was prepared as an account of work sponsored by an agency of the United States Government. Neither the United States Government nor the University of California nor any of their employees, makes any warranty, express or implicd, or assumes any legal liability or responsibility for the accuracy, completeness, or usefulness of any information, apparatus, product, or process disclosed, or represents that its use would not infringe privately owned rights. Refcrence herein to any specific commercial product, process, or service by trade name, trademark, manufacturer, or otherwise, does not necessarily constitute or imply its endorsement, recommendation, or favoring by the United States Government or the University of California. The views and opinions of authors expressed herein do not necessarily state or reflect those of the United States Government or the University of California, and shall not be used for advertising or product endorsement purposes.

Work performed under the auspices of the U. S. Department of Energy by the University of California Lawrence Livermore National Laboratory under Contract W-7405-Eng-48.

This report has been reproduced directly from the best available copy.

Available to DOE and DOE contractors from the Office of Scientific and Technical Information

P.O. Box 62, Oak Ridge, TN 37831

Prices available from (423) 576-8401 http://apollo.osti.gov/bridge/

Available to the public from the National Technical Information Service

U.S. Department of Commerce 5285 Port Royal Rd., Springfield, VA 22161 http://www.ntis.gov/

OR

Lawrence Livermore National Laboratory Technical Information Department's Digital Library http://www.llnl.gov/tid/Library.html 


\section{DISCI.AIMER}

This document was prepared as an account of work sponsored by an agency of the United Slates Government. Neither the United States Government nor the University of California nor any of their cmployees, makes any warranty, express or implied, or assumes any legal liability or responsibility for the accuracy, completeness, or usefulness of any information, apparatus, product, or process disclosed, or represents that its use would not infringe privately owned rights. Reference herein to any specific commercial product, process, or service by trade name, trademark, manufacturer, or otherwisc, does nol necessarily constitule or imply its endorsement, recommendation, or favoring by the United States Government or the University of Californin. The views and opinions of authors expressed herein do not necessarily state or reflect those of the United States Government or the University of California, and shall not be used for advertising or product endorsement purposes.s.

'This report has been reproduced directly from the best available copy.

Available to DOE and DOE contractors from the Office of Scientific and T'echnical Information P.O. Box 62, Oak Ridge, TN 37831

Prices available from (615) 576-8401, F']S 626-8401

Available to the public from the National Technical Information Service

U.S. Department of Commerce 5285 Port Royal Rd.

Springfield, VA 22161 


\title{
Analysis of Active Sensor Discrimination Requirements for Various Missile Defense Scenarios Final Report 1999 (99-ERD-080)
}

\author{
Arno G. Ledebuhr, Lawrence C. Ng, and Richard J. Gaughan
}

\section{Introduction}

During FY99, we have explored and analyzed a combined passive/active sensor concept to support the advanced discrimination requirements for various missile defense scenario. The idea is to combine multiple IR spectral channels with an imaging LIDAR (Light Detection and Ranging) behind a common optical system (see Figure 1). The imaging LIDAR would itself consist of at least two channels; one at the fundamental laser wavelength (e.g., the $1.064 \mu \mathrm{m}$ for Nd:YAG) and one channel at the frequency doubled (at $532 \mathrm{~nm}$ for Nd:YAG). A two-color laser output would, for example, allow the longer wavelength for a direct detection time of flight ranger and an active imaging channel at the shorter wavelength. The LIDAR can function as a high-resolution 2D spatial image either passively or actively with laser illumination. Advances in laser design also offer three color (frequency tripled) systems, high rep-rate operation, better pumping efficiencies that can provide longer distance acquisition, and ranging for enhanced discrimination phenomenology. New detector developments can enhance the performance and operation of both LIDAR channels. A real time data fusion approach that combines multi-spectral IR phenomenology with LIDAR imagery can improve both discrimination and aim-point selection capability. 


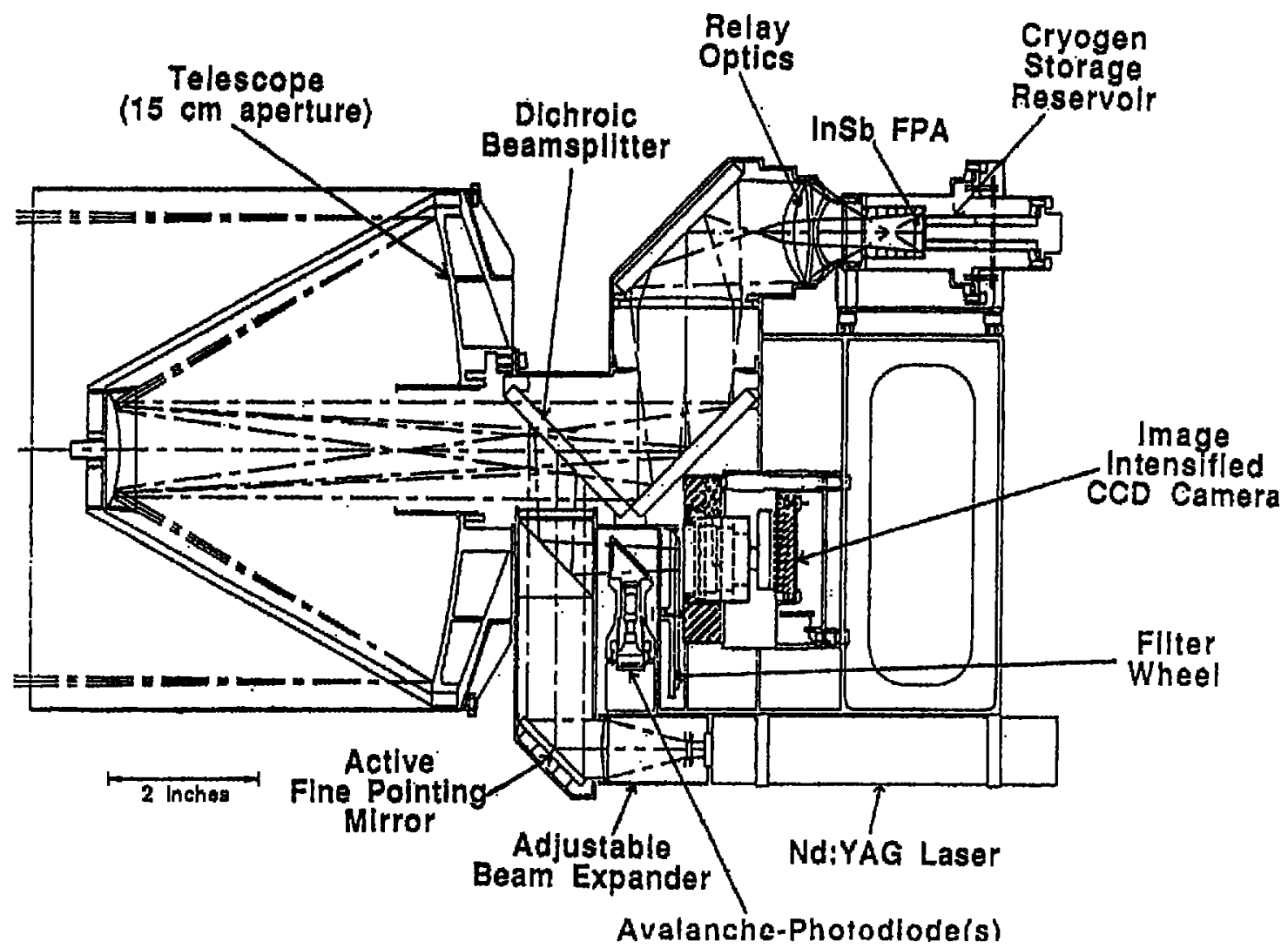

Figure 1. Discriminating Sensors Combine both Passive $I R$ and Active Imaging LIDAR in Integrated Package

\section{Ballistic Missile Simulation Toolkit}

We also procured the Satellite Tool Kit (STK) developed by the Analytical Graphics, Inc. in FY99. The STK software is a recognized Simulation tool used by the aerospace industry for high fidelity satellite orbital simulation. It also contains modules that can model various missile flight trajectories and global target tracking from both ground and space assets. Figure 2 shows a simulation of close by inspection maneuvers around an orbiting satellite. Figure 3 shows a realistic ballistic missile engagement using a Navy asset. With this tool, we have developed several engagement scenarios demonstrating a ballistic missile defense capability by intercepting an Intern Continental Ballistic Missile (ICBM) originating from a potential rouge state. We have also analyzed several ICBM intercept scenarios and showed the potential defense footprint for ship deployment at several potential hot spots. The simulation was developed to show the role that Navy could play in ballistic missile defense as shown in Figures 2 and 3 below. 
The simulation was demonstrated to a visiting Admiral and successfully showcased the capability of this analytic tool. We are continuing our effort in building high fidelity satellite and ballistic missile defense simulation capability using this tool acquired from these LDRD funds. In addition, some laser measurements were conducted to support the development of advanced discriminating LIDAR sensors for Ballistic Missile Defense (BMD) applications.

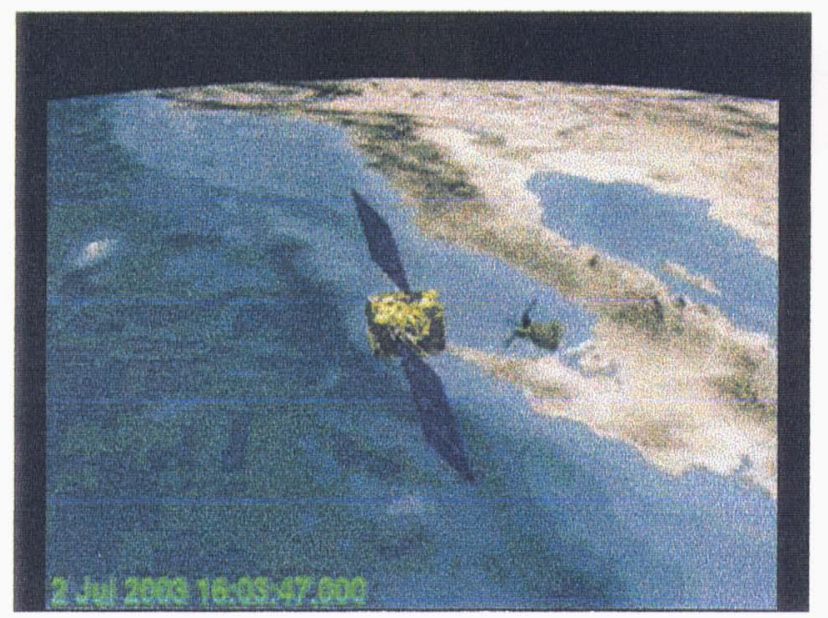

Figure 2. Satellite proximity maneuver simulation

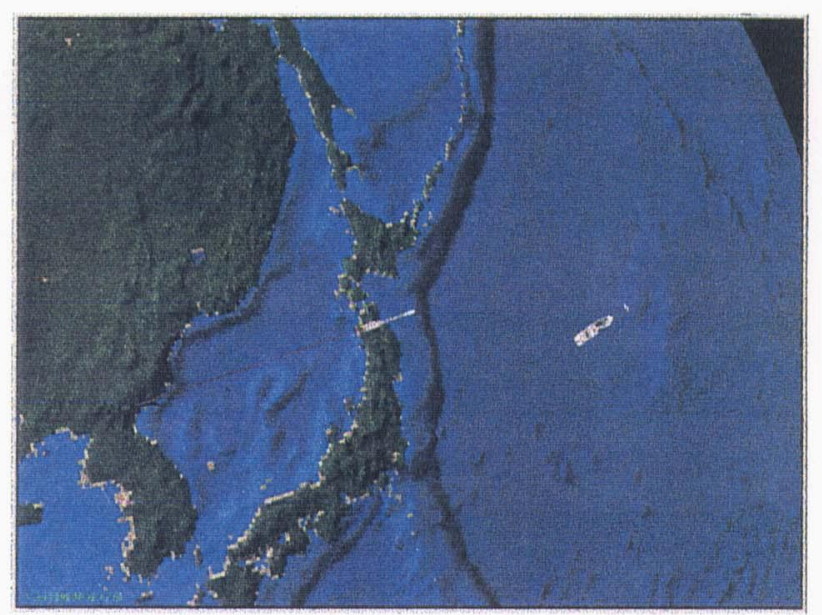

Figure 3. Ballistic missile defense simulation

\section{Detailed Discrimination Calculations}

Technological improvements in detector technologies and lightweight materials open up the possibility of improving missile interceptor performance with the introduction of low-mass, low-volume high-performance seekers. In fact, the next generation of countermeasures may compel the adoption of advanced technologies in the overall interceptor and specifically in the seeker. The following analysis outlines the discrimination capabilities that are provided by a multiple wavelength system.

The baseline system outlined here includes five optical channels, all sharing a common aperture. There is a $1.06 \mu$ active ranging LIDAR and a $532 \mathrm{~nm}$ active imaging system. There are three infrared detectors, one mid-wave and two long-wave. The mid-wave imager is sensitive to radiation in the $3-5 \mu$ band, while the long-wave systems sense $7-9$ and $9-11 \mu$ 
radiation. This analysis examined the utility of these channels for performing target discrimination. The initial promising results will be sketched here.

\section{Discriminating Balloons from Cones}

The signal electrons generated by the radiance detected from a thermal target are given by:

$$
\mathrm{n}_{\mathrm{s}}:=\mathrm{B} \cdot \frac{1}{\mathrm{BW}} \cdot:_{\mathrm{s}}: \mathrm{a}_{\mathrm{s}} \cdot \frac{\pi}{4} \cdot \frac{\phi_{\mathrm{o}}{ }^{2}}{\left(\mathrm{R} \cdot 10^{5}\right)^{2}} \cdot \tau \mathrm{o} \cdot \eta \cdot \int_{\lambda_{1}}^{\lambda,} \frac{\lambda \cdot 10^{-4}}{\mathrm{~h} \cdot \mathrm{c}} \cdot \mathrm{L}(\lambda, \mathrm{T}) \mathrm{d} \lambda
$$

where $\mathrm{B}$ is the optics blur fraction, BW is the detector bandwidth,

${ }^{\varepsilon} s_{\text {is the target emissivity, }}{ }^{a} s_{\text {is the target effective area, }}$

$\phi_{O}$ is the optical receiver diameter, $R$ is the range (in $\mathrm{km}$ ),

$\tau o_{\text {is the optics transmission, }} \eta_{\text {is the detector quantum efficiency, }}$

$\lambda$ is the wavelength (in $\mu$ ), $h$ is Planck's constant,

$c$ is the speed of light, and $L$ is the target spectral emissivity.

For a given system, the number of signal electrons within a specific spectral range is given by the area-emissivity product times the integrated spectral radiance, which is itself a function of temperature. This implies that two targets of different temperatures and emissivities may still generate the same signal for a given spectral band. For example, for the 9 to $11 \mu$ band, a one meter diameter sphere with an emissivity of nearly one at a temperature of $190 \mathrm{~K}$ generates nearly exactly the same number of electrons as a $2 \times 1$ meter cone with an emissivity of .25 at a temperature of $225 \mathrm{~K}$. That is, as shown in the figure, the two quite different targets have the same signature within the 9 to $11 \mu$ band. However, 


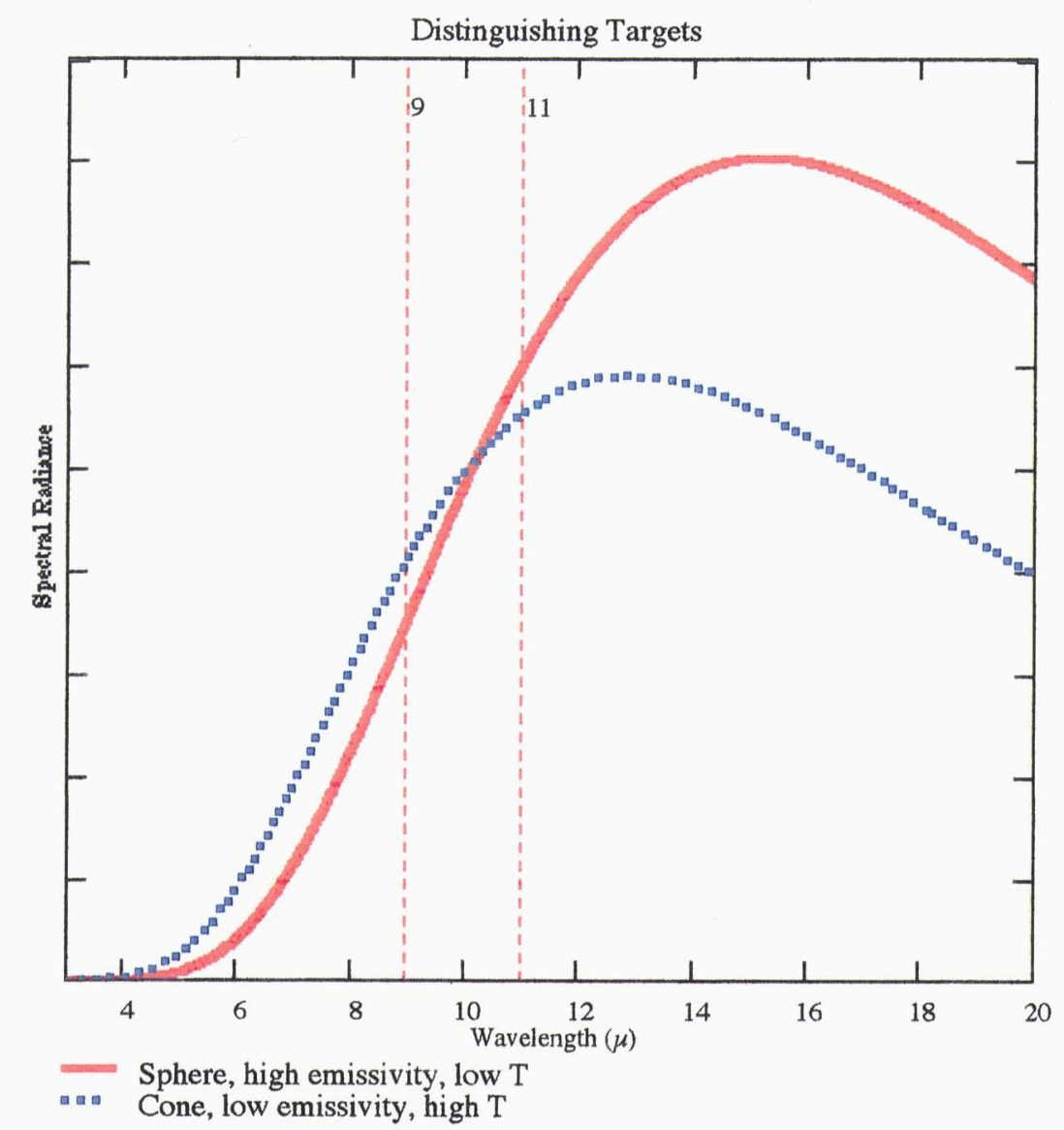

Figure 4. Spectral radiance for two objects at different spectral bands

when the signal from the 9 to $11 \mu$ band is compared to the signal generated in the 7 to $9 \mu$ band, the ratios for the two targets are significantly different.

\section{Discriminating Cones from Come-Like Decoys}

Sphere-like balloons are one potential decoy, but more sophisticated decoys are also possible. For example, decoys of similar shape to the RV cone may also be present. Such a decoy, if present, is postulated to exhibit dynamic behavior different from that of the true RV. The spinning bodies will precess about their direction of travel at the so-called "coning angle." Both the rate of precession and the coning angle will differ for the RV and the decoy. The visible imaging channel is sensitive to the aspect angle, the angle between the body axis and the direction of illumination. 
The signal returned from the actively illuminated cone is given by

$$
\begin{aligned}
& \text { where } \quad \mathrm{n}_{\mathrm{s}}:=\frac{1}{4 \cdot \pi \cdot \theta_{\mathrm{b}}^{2}} \cdot \cdots \mathrm{e}^{-\left[\frac{\varepsilon \mathrm{b}}{\theta_{\mathrm{b}}}\right]^{2}} \cdot \mathrm{A} \cdot \rho_{\mathrm{t}} \cdot \tau_{\mathrm{o}} \cdot \eta \cdot \frac{\phi_{\mathrm{o}}^{2}}{\left(\cdot 10^{3}\right)^{4}} \frac{\lambda \cdot 10^{-6}}{\mathrm{~h} \cdot \mathrm{c}} \theta_{\mathrm{b}_{\text {is the (circular) }}} \\
& \text { laser beam divergence half-angle, } \\
& \mathrm{E} \text { is the laser energy per pulse, } \\
& \varepsilon_{\mathrm{b}_{\text {is the pointing error, A is the effective target area, }}} \\
& \rho_{\mathrm{t}} \text { is the target reflectivity, and other parameters are defined as before. }
\end{aligned}
$$

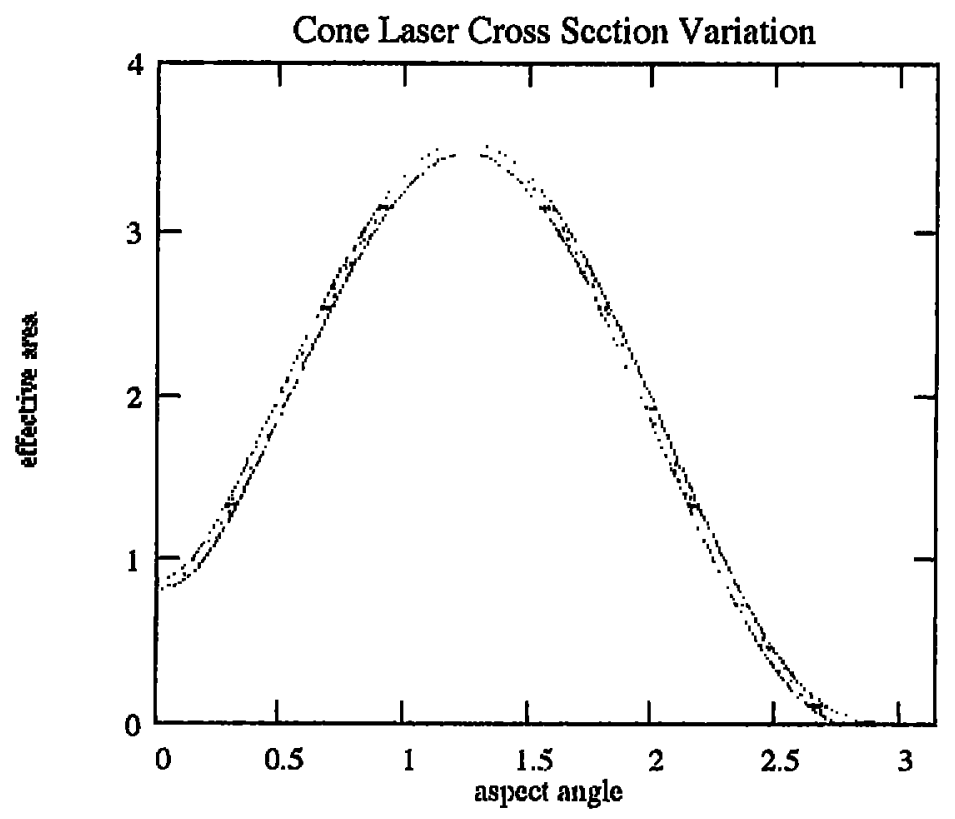

Figure 5. Cone laser cross section variation as a function of aspect angles

For a cone, the effective area is a function of cone angle and aspect angle ${ }^{1}$. The behavior of the functional form is shown in Figure 5. The precession about the direction of travel results in a periodic variation of the aspect angle.

The variation in aspect angle changes the effective area so that the signal return effectively varies as the cosine squared of the aspect angle. The returned signal for two identical 
cones is shown in Figure 6. The only difference between the two is the magnitude of the coning angle. One set of data represents a one by two meter cone with a two degree coning angle, the other is an identical cone at 10 degrees.

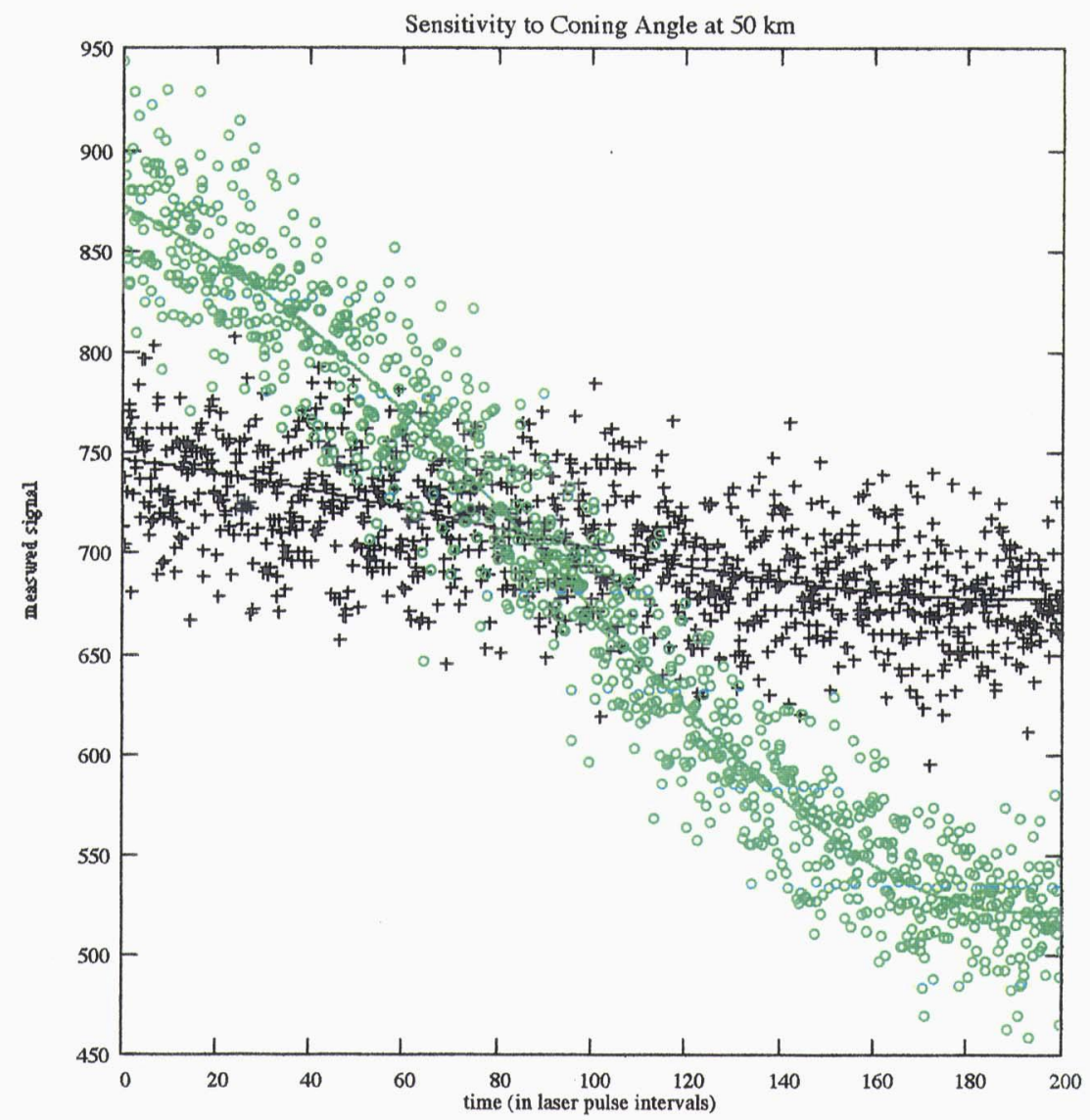

Figure 6. Simulated measured signal returns as a function of laser pulses

\section{Summary}

The representative results presented here show the utility of multiple sensor systems as discriminating seeker systems. The combined active/passive system would provide a robust spatial and spectral seeker subsystem to discriminate a target from a full spectrum of decoys differing in size, shape, spectral radiation, and coning motion. Further analysis will extend the performance modeling and allow the next level of detailed design to begin.

\footnotetext{
${ }^{1}$ MacFarland, et al, Laser Cross Section Handbook, WRDC-TR-89-9010
} 